\title{
Surgical management of breast cancer liver metastases
}

\author{
M. SABOL*, R. DONAT, P. CHVALNY, D. DYTTERT, J. PALAJ, S. DURDIK \\ Department of Surgical Oncology, Saint Elisabeth Cancer Institute, Faculty of Medicine-Comenius University, Bratislava, Slovak Republic \\ *Correspondence: martin.sabol@ousa.sk
}

Received October 25, 2013 / Accepted February 26, 2014

\begin{abstract}
We analyzed the treatment results in patients who underwent hepatic resection for breast cancer liver metastases(BCLM). Between 1/2003 and 12/2012, 15 patients underwent hepatic resection for BCLM. All primary breast tumors were diagnosed as invasive breast cancer. Synchronous BCLM ocurred in 2 patients and 13 patients presented with metachronous BCLM. Median age of patients at the time of BCLM diagnosis was 51 years(range from 31 to 73 years). All resections were considered as R0. From among 15 resections we performed 10 major hepatic resections according to Couinaud classification( $\geq 3$ segments) and the rest were minor ones. There was no postoperative mortality within 60 days . All postoperative complications were managed conservatively. Median hospital stay was 10,5 days, ranging from 7-14 days.

Standard therapy for patients with BCLM remains systemic chemo- and hormonal therapy. Hepatic resection as a part of multimodal treatment in tertiary HPB centers can offer in a selected group of patients a safe option for improved survival.
\end{abstract}

Key words: breast cancer, liver metastases, hepatic resection

Breast cancer is the most common malignancy among the women worldwide and the second leading cause of cancer-related deaths in the USA.[1] In 2008 the estimated number of newly diagnosed cases world-wide was 1,384,155 which represented $22,7 \%$ share of newly diagnosed cancers among women. In 2005, the number of breast cancer cases in females diagnosed in the Slovak Republic was 2,198, which represents ASR-W incidence of 52.2/100,000. [2] Metastatic breast cancer is considered as a systemic disease with predominant hematogenous spread of the tumor cells. Despite of new therapeutical modalities it still could not be regarded as a curable disease. Modern systemic regimens can provide response rates up to $60 \%$.[3 ] Liver is the third most common distant metastasis site in breast cancer patients. [4] The 4 most common reported anatomic sites of distant metastases are bone $(41,1 \%), \operatorname{lung}(22,4 \%)$, liver(7,3\%), and brain(7,3\%).[5] From among patients with noncolorectal nonendocrine tumors with liver metastases, patients with breast as a primary tumor site belongs to the group with favourable outcome following resection with 5-year and 10-year survival of $41 \%$ and 22\%, respectively. [6] Elias et al. [7] reports that liver metastases appear in cca half of women with metastatic breast cancer. Isolated BCLM occur in 4-5\% of metastatic breast cancer patients. $[8,9]$ Presence of liver metastases indicates a very poor prognosis with median survival time of only 48 months if left untreated.[10] In patients with BCLM who underwent hormone therapy or chemotherapy (Doxorubicín, Docetaxel,5-fluorouracil) median survival does not exceed 24 months. [11] It remains still questionable whether surgery plays an indispensable role in overall survival improvement in patients with BCLM.

\section{Patients and methods}

Between 1/2003 and 12/2012, 15 patients underwent hepatic resection for BCLM. Diagnosis of the primary tumor was histopathologically confirmed as an invasive breast cancer in every patient. Breast cancer staging was done according to the seventh edition of the International Union Against Cancer(UICC).[12 ] All of them were female patients who received either breast conserving surgery (lumpectomy,quad rantectomy) or modified radical mastectomy combined with axillar lymphadenectomy.

Statistic analysis. Data were collected prospectivelly and were retrospectively evaluated from our database. Statistic analysis was performed using XLSTAT2013 software and the Kaplan-Maier method was used for survival determination. 


\section{Results}

Characteristics of primary breast cancer. All 15 patients were females with a median age at the time of BCLM diagnosis of 51 years(range from 31 to 73 years). Primary tumor was referred as an invasive ductal type in $88 \%$ (12 patients) and $12 \%$ (3 patients) presented with invasive lobular carcinoma. High-grade cancer was identified in $47 \%$ of cases and the rest 53\% were grade 2 tumors. T1/2 tumors were present in $81 \%$, T4 tumors ocurred in $19 \%$ of patients. $50 \%$ of patients had positive axillary lymphnode status. Modified radical mastectomy combined with axillary lymphadenectomy was performed in 58\% and breast conserving procedure with axillary lymphadenectomy was performed in $42 \%$. Because of 2 cases of bilateral cancer one patient underwent bilateral modified radical mastectomy and the second one underwent unilateral mastectomy and contralateral breast conserving procedure.

Liver metastasis-specific data. Indication criteria for hepatic resection have been changing over the period of time of our study according to ability of systemic treatment (Navelbin+5FU/FA, Taxol, Avastin, Docetaxel, Femara, Herceptin, Xeloda) to stabilize the primary breast cancer disease. While some 10 years ago we had almost no patients with BCLM suitable for hepatic resection, in present we are dealing with breast cancer liver metastatic patients who are approved by multidisciplinary team for hepatic resection. Resection candidates were patients with good performance status with macroscopically safely resectable liver lesions. Before resection all the patients underwent CT, liver MRI with Primovist contrast media and bone scintigraphy. Study is a retrospective one. Written informed consent was obtained from each patient prior to hepatic resection.

Table 1. Characteristics of primary breast cancer

\begin{tabular}{ccccccc}
\hline Patient nr. & T & N & Grade & ER & PR & HER2 \\
\hline 1 & 2 & 0 & 2 & $0 \%$ & $0 \%$ & NR \\
2 & 4 & 1 & 2 & $0 \%$ & $0 \%$ & NR \\
3 & $1 / 2$ & $0 / 1$ & $3 / 3$ & $50 \% / 50 \%$ & $50 \% / 50 \%$ & NR \\
4 & $4 / 1$ & $1 / 0$ & $3 / 3$ & $50 \% / 75 \%$ & $50 \% / 50 \%$ & NR \\
5 & 2 & 2 & 3 & $90 \%$ & $15 \%$ & Posit. \\
6 & 2 & 1 & 2 & $30 \%$ & $0 \%$ & NR \\
7 & 1 & 0 & 2 & $70 \%$ & $30 \%$ & Posit. \\
8 & 2 & 1 & 2 & $0 \%$ & $0 \%$ & NR \\
9 & 2 & 2 & 3 & $75 \%$ & $50 \%$ & NR \\
10 & 4 & 1 & 3 & $50 \%$ & $0 \%$ & NR \\
11 & 2 & 0 & 2 & $0 \%$ & $0 \%$ & NR \\
12 & 2 & 0 & 2 & Posit. & Posit. & NR \\
13 & 1 & 0 & 2 & $0 \%$ & $0 \%$ & NR \\
14 & 2 & 1 & 2 & $0 \%$ & $0 \%$ & Posit. \\
15 & 1 & 1 & 3 & $0 \%$ & $0 \%$ & Posit. \\
\hline
\end{tabular}

Abbr: ER - estrogene receptor status, PR - progesterone receptor status, IDC - invasive ductal cancer, ILC - invasive lobular cancer, NR - not recorded.
Between 1/2003 and 12/2012 we performed overall 283 hepatic resections, including 15 resections for BCLM . Resections were considered as major with removal $\geq 3$ segments and as minor with removal $<3$ segments according to Couinaud classification. [13] Synchronous BCLM ocurred in 2 patients. In these patients hepatic resection was performed in the second step after breast surgery and adjuvant systemic treatment (Navelbin+5FU/FA, Taxol, Avastin, Docetaxel, Femara, Herceptin, Xeloda). 13 patients presented with metachronous BCLM. Median interval between breast surgical procedure and hepatic resection was 46,5 months(range 17 - 80 months). Interval between breast surgery and appearance of BCLM varied from 0 (synchronous presentation of BCLM) to 178,6 months (Table 2). In this interval all patients underwent systemic treatment targeted for breast cancer and 5 patients underwent neoadjuvant chemotherapy before hepatic resection for BCLM. 5 patients with BCLM and stabilized extrahepatic disease were included in the study ( 1 patient with resectable pulmonary metastasis that was resected 2 months later, 2 patients with stabile skeletal lesions, 1 patient with ovarian metastasis was treated simultaneously by ovarectomy, 1 patient with triplex primary tumor: ovarian, renal and breast cancer - ovarian and renal ones treated before, she had past history of hysterectomy and bilateral adnexectomy and nefrectomy for renal cancer). Median size of liver metastases was $22 \mathrm{~mm}$ (range $2-66 \mathrm{~mm}$ ). Number of metastatic lesions ranged from 1 to 5 , solitary lesion was present in 9 patients, 3 lesions in three patients, 4 lesions in two patients and 5 lesions ocurred in one patient. Distribution of the liver lesions was unilobar in 9 cases while in 6 patients was bilobar. Resection margin was more than $10 \mathrm{~mm}$ in all cases. Imunohistochemistry of hepatic lesions revealed steroid

Table 2. Characteristics of metastatic liver lesions in BCLM patients

\begin{tabular}{ccccc}
\hline $\begin{array}{c}\text { Patient } \\
\text { Nr. }\end{array}$ & $\begin{array}{c}\text { Interval to } \\
\text { diagnosis of } \\
\text { BCLM/months }\end{array}$ & $\begin{array}{c}\text { Interval from } \\
\text { diagnosis of } \\
\text { BCLM to surgery } \\
\text { / months }\end{array}$ & $\begin{array}{c}\text { Extrahepatic } \\
\text { disease }\end{array}$ & S/M \\
\hline 1 & 0 & 6,6 & Ovarian cancer + & $\mathrm{S}$ \\
& & & renal cancer & \\
2 & 0 & 3,2 & 0 & $\mathrm{~S}$ \\
3 & 55,6 & 0,93 & 0 & $\mathrm{M}$ \\
4 & 178,6 & 5,4 & 0 & $\mathrm{M}$ \\
5 & 73,2 & 2,1 & lungs & $\mathrm{M}$ \\
6 & 85,1 & 1 & skeletal & $\mathrm{M}$ \\
7 & 64,1 & 0,5 & 0 & $\mathrm{M}$ \\
8 & 15,1 & 0,5 & 0 & $\mathrm{M}$ \\
9 & 15 & 1,1 & 0 & $\mathrm{M}$ \\
10 & 38,1 & 1,2 & 0 & $\mathrm{M}$ \\
11 & 96,5 & 9,3 & 0 & $\mathrm{M}$ \\
12 & 78,3 & 0,4 & ovary & $\mathrm{M}$ \\
13 & 119,4 & 50,2 & skeletal & $\mathrm{M}$ \\
14 & 33,1 & 4,8 & 0 & $\mathrm{M}$ \\
15 & 49,3 & 2,3 & 0 & $\mathrm{M}$ \\
\hline
\end{tabular}

Abbr.: S - synchronous BCLM, M - metachronous BCLM 
receptor (SR) positivity in 7 patients, 5 were SR negative and in 3 patients SR status was not determined.

Hepatic resection procedures. All hepatic resections were considered as R0. From among 15 resections we performed 10 major hepatic resections according to Couinaud classification( $\geq 3$ segments) and the rest were minor ones. From among 10 major resections we performed right hepatectomy in 5 patients, right extended hepatectomy in 1 patient, left hepatectomy in 3 patients and central hepatic resection $(S 4,5,8)$ in 1 patient. Left lateral bisegmentectomy was performed once, anatomic segmentectomy $(\mathrm{S} 3,4)$ in 1 patient, metastasectomy in 2 patients and in one patient we performed right portal branch ligature in combination with metastasectomy.

Mortality and morbidity. We have analysed postoperative morbidity and mortality that was defined as a complication ocurred within 60 days after operation. We did not encounter postoperative mortality within 60 days after resection. All postoperative complications were managed conservatively. Subphrenic abscess and biliary collection at the resection surface in one patient was drained under CT guidance, reactive pleural effusion resolved after drainage, 1 transient hepatic insufficiency was managed successfully in ICU. Hospital stay duration ranged from 7-14 days, with median of 10,5 days.

Overall survival - Median of overall survival in our patients was 52,7 months(range 9,2 - 79,8 months).

1 , 3, a 5 -years survival was $100 \%, 67 \%$ and $38 \%$, respectively.

We did not find significant difference in 1, 3 and 5-years survival in patients with synchronous vs. metachronous $\operatorname{BCLM}(\mathrm{p}=0,606)$.

Concerning the time of the appearance of liver metastases we did not find significant difference $(p=0,373)$ in 1 - , 3 - and
Survival distribution function

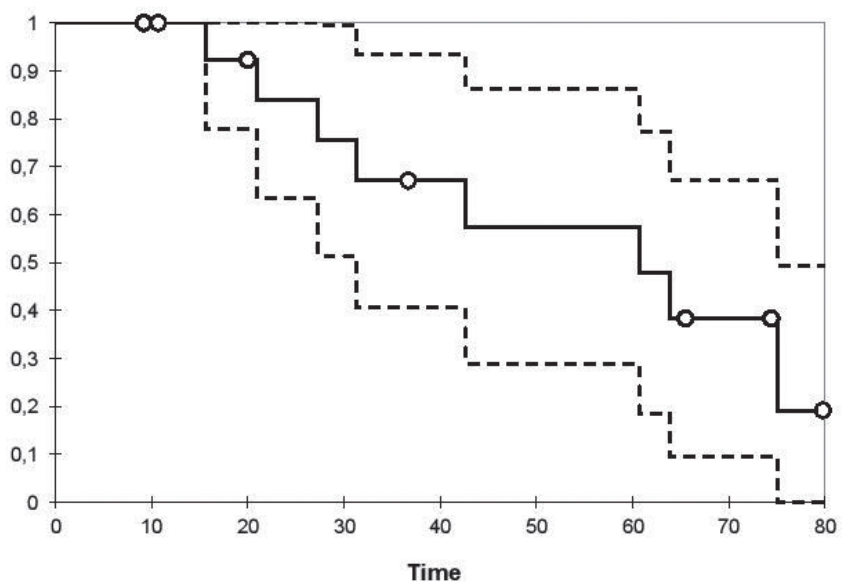

Figure 1. Overall survival curve of patients with BCLM

5-years survival between the groups of patients with BCLM development prior to 50 months (A in Fig. 3) in comparison with the one after 50 months (B in Fig.3).

Follow up/recurrence. 8 patients (53\%) died during the follow up, all of them because of dissemination. During follow up we noted 6 cases with BCLM recurrence (disease free interval 6,9-15,9 months). In two patients brain and osseal metastatic lesions appeared. 7 patients are still alive with median of survival 36,7 months ( range 9,2-79,8 months). In one of these patients hepatuoduodenal ligament lymphadenopathy was revealed and in one BCLM recurred. Totally 5 patients are alive without signs of disease recurrence.

Table 3. Type of hepatic resection procedure

\begin{tabular}{|c|c|c|c|c|c|}
\hline Patient Nr. & Age/years & Procedure & Resection margin & Postop. complication & Hospital stay/days \\
\hline 1 & 51 & Left lateral bisegmentectomy S2,3 & $>10 \mathrm{~mm}$ & 0 & 11 \\
\hline 2 & 57 & Left hepatectomy & $>10 \mathrm{~mm}$ & 0 & 10 \\
\hline 3 & 43 & Right hepatectomy & $>10 \mathrm{~mm}$ & 0 & 11 \\
\hline 4 & 43 & Mts-ectomy S4A & $>10 \mathrm{~mm}$ & 0 & 7 \\
\hline 5 & 51 & Segmentectomy S3,4 & $>10 \mathrm{~mm}$ & 0 & 9 \\
\hline 6 & 49 & Right extended hepatectomy & $>10 \mathrm{~mm}$ & 0 & 11 \\
\hline 7 & 33 & $\begin{array}{l}\text { Central resection } \\
\qquad(\mathrm{S} 4,5,8)\end{array}$ & $>10 \mathrm{~mm}$ & 0 & 7 \\
\hline 8 & 31 & $\begin{array}{c}\text { Mts-ectomy }+ \text { right portal branch } \\
\text { ligation }\end{array}$ & $>10 \mathrm{~mm}$ & 0 & 8 \\
\hline 9 & 66 & Right hepatectomy & $>10 \mathrm{~mm}$ & Subphrenic absces & 8 \\
\hline 10 & 48 & Right hepatectomy 0 & $>10 \mathrm{~mm}$ & 0 & 14 \\
\hline 11 & 61 & Left hepatectomy & $<10 \mathrm{~mm}$ & 0 & 10 \\
\hline 12 & 61 & Right hepatectomy & $>10 \mathrm{~mm}$ & Fluidothorax+hepatorenal syndrome & 14 \\
\hline 13 & 55 & Right hepatectomy & $>10 \mathrm{~mm}$ & 0 & 15 \\
\hline 14 & 45 & Mts-ectomy & $>10 \mathrm{~mm}$ & 0 & 8 \\
\hline 15 & 45 & Left hepatectomy & $>10 \mathrm{~mm}$ & Fluidothorax, biloma & 20 \\
\hline
\end{tabular}


Survival distribution function

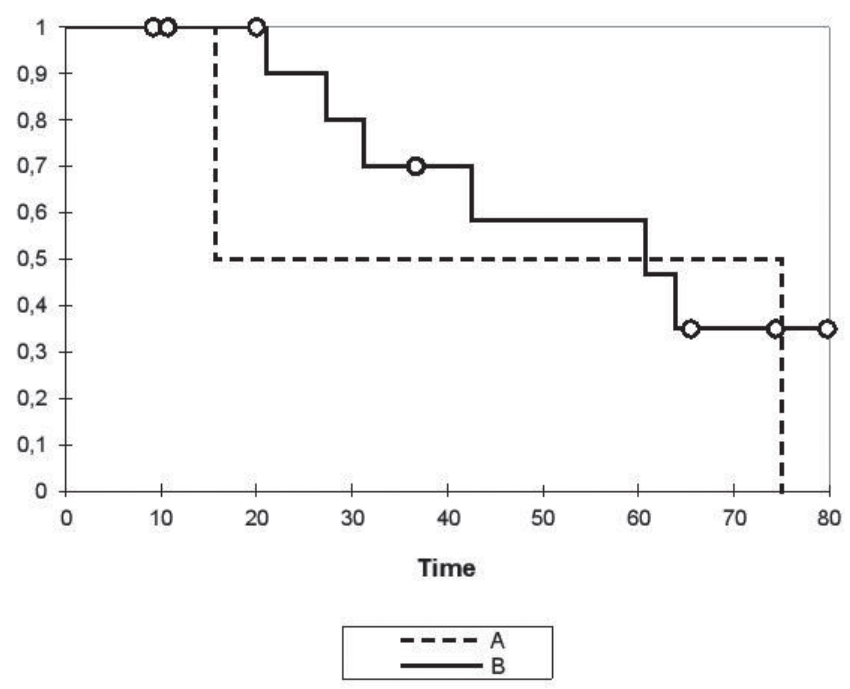

Figure 2. Synchronous(A) and metachronous(B) breast cancer liver metastases. Survival distribution function.

\section{Discussion}

According to the autopsy studies done by Lee [14], liver is the third most common site of breast cancer metastases (50-71\%) after the lung (55-77\%) and bone (49-74\%). Breast represents the most common primary tumor site in the patients with noncolorectal nonendocrine liver metastases. [6] According to the various studies the number of patients with BCLM who underwent hepatic resection range from 6 to 85 with 5 -years survival $18,4 \%-61 \%$ whereby the largest study comes from Adam et al. [10] in 2006 who reports $37 \% 5$-years survival and a median survival of 32 months in patients after surgery. Patients with BCLM are often included in the studies dealing with noncolorectal nonneuroendocrine liver metastases. In general, these studies comprise heterogenous groups of relatively small number of patients with different neoadjuvant and adjuvant treatment, with both synchronous and metachronous liver lesions. One of the parameters significantly influencing patients' survival after hepatic resection for BCLM is time interval between breast surgery for primary tumor and development of liver metastases. Majority of the series proved the fact that the longer time interval was the better survival ocurred. [15,16] Pocard et al. [17] reported 3-years survival of 55\% when BCLM appeared in $\leq 48$ months in comparison with 3-years survival of $85 \%$ when BCLM appeared after 48 months. Multivariate analysis showed prognostic relevance for the time interval between the primary diagnosis of breast cancer and the appearance of liver metastases $(p<0.05)$. [18] However, in our study we did not find significant difference in 1- , 3- and 5 -years survival between the groups of patients with BCLM
Survival distribution function

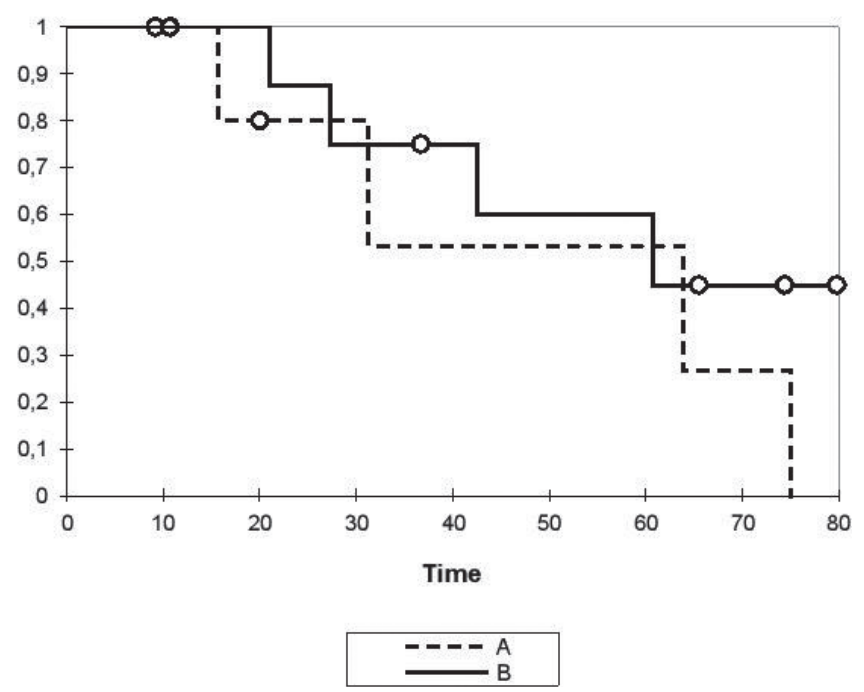

Figure 3. Comparison of survival according to the time of BCLM appearance

development prior to 50 months vs. after 50 months. Hepatic resection in patients with extrahepatic disease still remains controversial. In the study by Sakamoto et al. [19], presence of extrahepatic disease was the only prognostic factor of a poor outcome - no patient with extrahepatic disease survived 5 years but 5 -year survival of patients without extrahepatic disease was $31 \%$. In our study there were included 5 selected patients with stabilized extrahepatic disease: 1 patient with resectable pulmonary metastatic lesion, 2 patients with stabile skeletal lesions, 1 patient with ovarian metastasis and 1 patient with triplex primary tumor (ovarian, renal and breast cancer). Based on our opinion extrahepatic resectable disease should not be considered as an obstacle for hepatic resection. Small differences in survival were observed among patients with R0 and R1 resections. [9] According to histopathology reports all hepatic resections for BCLM in our study were considered as R0. In present breast cancer is not considered as a homogenous disease group but rather as a number of various subtypes with different features and distinct prognosis. It was reported that HER2-enriched subtype breast cancers agressively spread to the liver.[20] Gene expression studies have even identified subtype-specific predilections to distant metastatic site.[21] According to the phenotype, patients with basal-like or triple-negative breast cancers experience reduced disease-free and overall survival relative to other breast cancer subtypes.[22] Single-institution retrospective study of breast cancer liver metastases patients from Tianjin China reported 1-, 2- and 3-years survival rate 68.3, 48.0 and $34.1 \%$, respectively with a median survival of 29 months. Results from this cohort study showed that triple-negative patients posses the worst survival when liver metastases oc- 
cur in comparison with non-triple-negative subtypes . [23] In French study overal surival 1-, 3, a 5-years rate were 94, 69 and 33\%, respectivelly. Analysis revealed that hormone receptor status, number of lesions, major hepatectomy and younger age were factors of a poor prognosis. [24] Concerning steroid receptor status in the present study $41 \%$ of the primary breast tumors were considered as ER negative and 53\% PR negative. Another predictive factor is the status of hilar lymph nodes in patients with BCLM. However, studies did not revealed any significant differences in survival between hilar lymph-node positive and node-negative BCLM patients.[19,25,26]

Metastatic breast cancer, as it was emphasized above, is considered as a systemic disease and the re-appearance of liver lesions /or extrahepatic spread in previously resected BCLM patients is not rare. That is a reason why systemic treatment plays a crucial role in successful management of these patients. Unfortunately liver metastases are generally considered to be less responsive to chemotherapy than metastases at other sites and these patients with liver metastases have often worse survival in comparison with patients with metastatic spread to other organs.[27]

Standard therapy for patients with BCLM still remains systemic chemo and hormonal therapy (Navelbin+5FU/FA, Taxol, Femara, Avastin, Docetaxel,Herceptin,Aromasin). However advances in liver resection techniques, improvements in imaging tools, evolution in anesthetic and perioperative management have widely extended indication criteria for hepatic resections. Hepatic resection as a part of multimodal treatment in tertiary HPB centers has become a safe procedure with low rate of complications and can offer an option for improved survival in a selected group of BCLM patients. Liver resection is recently considered as a local adjuvant treatment of the liver in responders to systemic treatment. Pocard et al. [28] has denoted this treatment strategy as an ,adjuvant surgery“. On the contrary disease progression during preoperative systemic treatment is considered as a contraindiction to surgery. Limited series of patients resected for BCLM, often heterogenous groups of patients included in the series and the lack of prospective randomized trials keeps the question of impact of hepatic resection on overall survival in BCLM patients open.

Acknowledgements: This study was supported by St. Elisabeth Cancer Institute, Bratislava.

\section{References}

[1] JEMAL A, SIEGEL R, XU J, WARD EL. Cancer statistics, 2010 CA Cancer J Clin 2010 Sep-Oct; 60: 277-300. http://dx.doi. org/10.3322/caac. 20073

[2] ONDRUSOVA M., Muzik J., Durdik S.,Ondrus D. Long-term trends in the development of the epidemiology of breast cancer in the Slovak and Czech Republic with reference to applied screening and international comparisons.Neoplasma,2012; 59: 70-8. http://dx.doi.org/10.4149/neo 2012 009
[3] CURLEY SA, PICCART MJ, WOOD WC, HUNG MC, SOLIN LJ, CARDOSO F. Surgical management of BCLM, breast cancer and molecular medicine, Springer 2006 pp 525-543.

[4] INSA A, LLUCH A, PROSPER F, MARUGAN I, MARTINEZAGULLO A et al. Prognostic factors predicting survival from first recurrence in patients with metastatic breast cancer: analysis of 439 patients. Breast Cancer Res Treat 1999; 56: 67-78. http://dx.doi.org/10.1023/A:1006285726561

[5] ABIGAIL T. BERMAN, ARPI D.THURKRAL, WEI-TING HWANG, LAWRENCE J. SOLIN, NEHA VAPIWALA. Incidence and Patterns of Distant Metastases for Patients With Early-Stage Breast Cancer After Breast Conservation Treatment. Clinical Breast Cancer 2013,Vol.13, No.2, 88-94. http://dx.doi.org/10.1016/j.clbc.2012.11.001

[6] ADAM R, CHICHE L, ALOIA, ELIAS D, SALMON RJ et al. Hepatic Resection for Noncolorectal Nonendocrine Liver metastases. Analysis of 1452 patients and development of a prognostic model. Ann Surg 2006; 244: 524-535.

[7] ELIAS D, DI PIETROANTONIO D. Surgery for liver metastases from breast cancer. HPB 2006; 8: 97-99. http://dx.doi. org/10.1080/13651820500471871

[8] ELIAS D, LASSER P, SPIELMAN M, MAY-LEVIN F, EL MALT $O$ et al. Surgical and chemotherapeutical treatment of hepatic metastases from carcinoma of the breast. Surg Gynecol Obstet 1991; 172: 461-464.

[9] DIAZ R, SANTABALL A, MUNARRIZ S, CALDERERO V. Hepatic resection in breast cancer metastases: Should it be considered standard treatment? Breast 2004; 13: 254-258. http://dx.doi.org/10.1016/j.breast.2003.11.001

[10] ADAM R, ALOIA T, KRISSAT J, BRALET MP, PAULE B et al. Is liver resection justified for patients with hepatic metastases from breast cancer? Ann Surg 2006(6); 244: 897-907. http://dx.doi.org/10.1097/01.sla.0000246847.02058.1b

[11] AAPRO MS. Combining new agements with antracyklins in metastatic breast cancer: an overview of recent findings. Semin Oncol 1999; 26: 17-21.

[12] SOBIN LH, GOSPODAROWITZ MK, WITTEKIND CH. TNM Classification of malignant tumors, Seventh edition. West Sussex: John Wiley\&Sons Ltd, 2010.

[13] J. E. SKANDALAKIS, L. J. SKANDALAKIS, P. N. SKANDALAKIS, P. MIRILAS. Hepatic surgical anatomy. Surg Clin N Am 84 (2004) 413-435 http://dx.doi.org/10.1016/ j.suc.2003.12.002

[14] LEE YT. Breast carcinoma: pattern of recurrence and metastasis after mastectomy. Am J Clin Oncol 1984; 7: 443-9. http://dx.doi.org/10.1097/00000421-198410000-00010

[15] VLASTOS G, SMITH D, SINGLETARY SE, MIRZA NQ, TUTTLE TM et al. Long-term survival after an aggressive surgical approach in patients with breast cancer hepatic metastases. Ann Surg Oncol 2004; 11: 869-74. http://dx.doi. org/10.1245/ASO.2004.01.007

[16] SELZNER M, MORSE MA, VREDENBURGH JJ, MEYERS WC, CLAVIEN PA. Liver metastases from breast cancer: long term survival after curative resection. Surgery 2000; 127 : 383-9. http://dx.doi.org/10.1067/msy.2000.103883

[17] POCARD M, POUILLART P, ASSELAIN B, FALCOU MC, SALMON RJ. Hepatic resection for breast cancer metastases: 
results and prognosis(65 cases). Ann Chir 2001; 126: 413-20. http://dx.doi.org/10.1016/S0003-3944(01)00526-0

[18] EICHBAUM MH, KALTWASSER M, BRUCKNER T, DE ROSSI TM, SCHNEEWEISS A et al. Prognostic factors for patients with liver metastases from breast cancer. Breast Cancer Res Treat. 2006; 96: 53-62. http://dx.doi.org/10.1007/s10549005-9039-1

[19] SAKAMOTO Y, YAMAMOTO J, YOSHIMOTO M, KASUMI F, KOSUGE T et al. Hepatic resection for metastatis breast cancer: prognostic analysis of 34 patients. World J Surg 2005; 29: 524-527. http://dx.doi.org/10.1007/s00268-004-7688-6

[20] HARRELL JC, PRAT A, PARKER JS, FAN C, HE X et al. Genomic analysis identifies unique signatures predictive of brain, lung and liver relapse. Breast Cancer Res Treat 2012; 132: 523-35. http://dx.doi.org/10.1007/s10549-011-1619-7

[21] SMID M, WANG Y, ZHANG Y, SIEUWERTS AM, YU J et al. Subtypes of breast cancer show preferential site of relapse. Cancer Res 2008; 68: 3108-3114. http://dx.doi.org/10.1158/ 0008-5472.CAN-07-5644

[22] HAFFTY BG, YANG Q, REISS M, KEARNEY T, HIGGINS SA et al. Locoregional relapse and distant metastasis in conservatively managed triple-negative early-stage breast cancer. J Clin Oncol 2006; 24: 5652-5657. http://dx.doi.org/10.1200/ JCO.2006.06.5664
[23] DUAN XF, DONG NN, ZHANG T, LI Q. The prognostic analysis of clinical breast cancer subtypes among patients with liver metastases from breast cancer. Int J Clin Oncol 2013; 18: 26-32. http://dx.doi.org/10.1007/s10147-011-0336-x

[24] LUBRANO J, ROMAN H, TARRAB S, RESCH B, MARPEAU L et al. Liver resection for breast cancer metastases: Does it improve survival? Surg Today 2008; 38: 297-299. http://dx.doi. org/10.1007/s00595-007-3617-2

[25] ELIAS D, MAISONNETTE F, DRUET-CANANAC M.,QUELLET JF., GUINEBRETIERE JM. et al. An attempt to clarify indications for hepatectomy for liver metastases from breast cancer. Am J Surg 2003; 185: 158-164. http://dx.doi. org/10.1016/S0002-9610(02)01204-7

[26] YOSHIMOTO M, TADA T, SAITO M, TAKAHASHI K, UCHIDA Y et al. Surgical treatment of hepatic metastases from breast cancer. Breast Cancer Res Treat 2000; 59: 177-184. http://dx.doi.org/10.1023/A:1006398401352

[27] FUMOLEAU P. Treatment of patients with liver metastases. Anticancer Drugs 1996; 7 Suppl 2: 21-3 http://dx.doi. org/10.1097/00001813-199608002-00006

[28] POCARD M, FALCOU MC, SALMON RJ. On the prognosis criteria for hepatic resection in cases of breast metastasis. Surgery 2001; 129: 651-2. http://dx.doi.org/ $\underline{10.1067 / \mathrm{msy} .2001 .114552}$ 